\title{
Savunma Sanayinde Kullanılan İleri Kompozit Malzemeler ve Uygulama Alanları
}

\author{
Erdem ERYILDIZ ve Ayşegül Akdoğan EKER \\ Yıldız Teknik Üniversitesi, Makine Mühendisliği Bölümü, 34349, İstanbul, Türkiye \\ eryildiz@yildiz.edu.tr
}

\begin{abstract}
Composites are materials that obtained by bringing together two or more different materials in a certain ratio and appropriate circumstances to gain the desired purpose. Due to the high strength/density ratio, composites are widely used. Their low density contributes fuel economy savings in vehicles and advantageously to increase speed. Also because of their low density, military equipments such as armours, weapons can be carried with less effort. The applications of composites in defence industry are increasing. The composite materials which are used in military aircrafts such as planes, helicopters; armoured vehicles such as tanks and panzers; heavy trucks for using military transportation, bullet proof vest, weapon bodies are used more and more in different applications. In recent years, with developing technology, the role and application areas of composite materials in defence industry are increasing rapidly. The use of composite materials in liquid armour, unmanned aerial vehicle, tank and aircraft armour, aircraft tail and wing components and landing field makes significant contributions to the development of the defence industry. In this study, the benefits of composite materials in the defence industry and its applications are discussed in detail.
\end{abstract}

Özet- İki veya daha fazla malzemenin, istenilen amaca yönelik olarak belli oran ve koşullarda bir araya getirilmesiyle elde edilen kompozit malzemeler, mukavemet/yoğunluk oranının yüksek olması nedeniyle yaygın kullanım alanı bulmaktadır. Düşük özgül ağırlıkları ile taşıtlarda yakıt ekonomisi, hız; taşınması gereken zırh, silah gibi askeri ekipmanlarda da taşıma kolaylığı ve buna bağlı olarak hareket kabiliyeti sağlamaktadır. Savunma sanayinde kompozit malzemelerin uygulama alanları, giderek artmaktadır. Uçak, helikopter gibi askeri hava taşıtlarında, tank, panzer gibi zırhlı araçlarda, askeri taşımacılıkta kullanılan ağır vasıtalarda, kurşungeçirmez yeleklerde, silah gövdelerinde kompozit malzemeler, gün geçtikçe daha fazla ve daha farklı uygulama biçimleriyle kullanılmaktadır. Son yıllarda gelişen teknoloji ile beraber ileri kompozitlerin savunma sanayindeki yeri ve uygulama alanları hızla artmaktadır. İleri kompozitlerin sıvı zırhlarda, insansız hava araçlarında, tank ve hava araçları zırhlarında, hava araçlarının kanat ve kuyruk elemanlarında ve iniş-kalkış pistlerinde kullanılması, savunma sanayinin gelişmesine önemli katkılar sağlamaktadır. Çalışmada, kompozit malzemelerin savunma sanayinde sağlayacağı avantajlar ve uygulamaları ayrıntılı olarak ele alınmıştır.

\section{GİRIŞ}

$\mathrm{K}$ ompozit malzemeler, şekil ve/veya kimyasal bileşenleri farkl1, birbiri içerisinde pratik olarak çözünmeyen iki veya daha fazla sayıda makro bileşenin kombinasyonundan oluşan malzemeler şeklinde tanımlanmaktadır [1].

Kompozit malzeme üretiminin bilinçli olarak ele alınması ve bilimsel yaklaşımlarla yeni malzemelerin geliştirilmesi ancak 1940'lı yıllarda cam takviyeli plastiklerin kullanımı ile başlamıştır. Radar kubbeleri, önemli ilk uygulamalara örnek olarak gösterilebilir. 1950'lerde uçak pervaneleri kompozit malzemeden yapılmaya başlanmıştır [2].

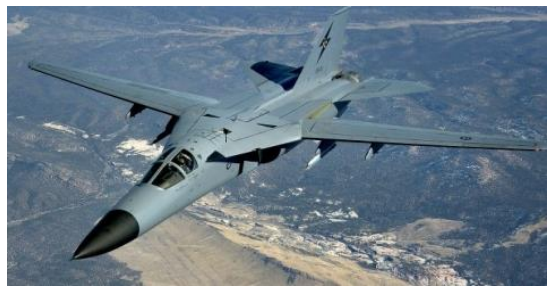

Şekil 1. General Dynamics Tarafindan Üretilen F111C A8-131

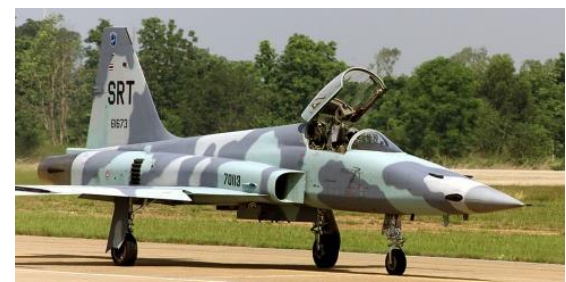

Şekil 2. General Dynamics Tarafindan Üretilen Northrop F-5E Tiger II

Günümüzde uçak endüstrisinde, kompozit malzeme kullanımı \% 30 oranlarına ulaşmıştır. General Dynamics firmasının ürettiği F-111'lerin (Şekil-1) gövdesinde bor-epoksi çifti, Northrop F5'lerin (Şekil-2) gövdelerinde grafit-epoksi çifti kullanılmıştır. Ayrıca Grumman F-14 ve McDonnellDouglas F-15'lerde kullanılan bor-epoksi, General Dynamics'e ait YF- 16'larda kullanılan karbon-epoksi esaslı kompozitler, örnek olarak verilmektedir. Alüminyum içine dizilmiş bor lifleri, $1000{ }^{\circ} \mathrm{C}$ üzerindeki sıcaklıklarda çalışan ve nikelalüminyum alaşımı içerisinde oluşturulmuş nikel-niobyum levhaları ile kuvvetlendirilen malzemeler, uçak sanayinde kullanılan diğer kompozit malzemelerdir. Kompozit malzemeler üzerine yapılan çalışmalar yoğun olarak devam etmekte olup özellikle gelişen teknolojinin malzeme gereksinimini karşılamak için tek çözüm olarak bu malzemeler görülmektedir [3]. 


\section{Savunma Sanayinde Kullanılan İleri Kompozit Malzemeler} ve Uygulama Alanları

Savunma sanayinde kullanılmak amaciyla üretilen kompozit malzemelerden beklenen özellikler, yüksek mukavemet/yoğunluk oranı, şekillendirebilme, elektriksel özellikler, korozyona ve kimyasal etkilere karşı mukavemet, renklendirilebilme ve titreşim sönümlendirmedir.

Uçak, helikopter gibi askeri hava taşıtlarının kanat ve kuyruk elemanlarında ve iniş-kalkış pistlerinde, egzoz flaplerinde, tank, panzer ve hava taşıtlarının zırhlarında, askeri taşımacılıkta kullanılan ağır vasıtalarda, vücut koruyucu hafif zırhlarda, kurşungeçirmez yeleklerde, silah gövdelerinde, sıv1 zırhlarda, insansız hava araçlarında, otobüs, kamyon ve diğer askeri araç koltuklarında ve yanmaz askeri çadırlarda kompozit malzemeler tercih edilmektedir.

\section{A. Sivı Zirh}

Geleneksel zırhlar katı formdadır. Sıvı zırhlar ise normal koşullar altında sıvı formdadır fakat vurulma anında sertleşir. Zırhın normal koşullarda sıvı olması, kişinin rahat hareket etmesini sağlar. Bu sıvı malzemelere, "kesme gerilmesi altında sertleşen" malzeme (Shear Thickening Fluid) denir. Koruyucu zırhlarda kullanılan bu sıvılar, kurşunun yanı sıra ok ve bıçak gibi darbelerde de koruyucu nitelik göstermektedir [4].

Ülkemizde, sıvı zırh konusunda çalışmalar bulunmaktadır. Sıvı zırhın pratikte kullanılmasına en büyük sorunu raf ömrü teşkil etmektedir. Bu nedenle, koruyucu özelliklerini kaybetmeyecek şekilde sıvı zırhın kullanım ömrünü uzatma konusunda çalışmalar devam etmektedir.

B. Tank ve Hava Taşıtları İçin Zırh

Kompozit malzemeler, askeri taşıtlarda ağırlığı azaltırken bekayı arttırır. $30 \mathrm{~mm}$ kalınlığında karbon fiber takviyeli kompozitten imal edilen bir uçak gövdesi, sert çelikten yapılmış gövdenin karşıladığı gibi gelen tehditleri karşılar ve çelikten yapılan bu gövdeye göre \%10 daha hafif olmaktadır [4].

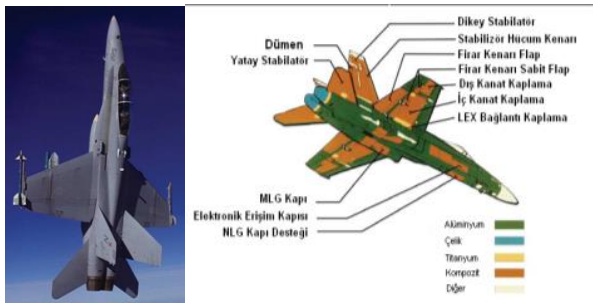

Şekil-3 F/A 18 Hornet Savaş Uçağındaki İleri Kompozit Uygulamaları [4]

C. Askeri Taşıma Araçlarında Takviyelendirilmiş Termoplastikler

Askeri taşıma araçlarında, ağır vasıtalarda çeşitli kompozitler uygulama alanı bulmaktadır. Bu kompozitlerden biri de sürekli fiber takviyeli termoplastiklerdir. Zemin ve yan paneller, bagaj, kompartıman, koltuk bileşenleri, kompozit malzemelerin giderek artan kullanım alanlarındandır. Şasi, süspansiyon, aktarma organları ve tekerlekler bir kamyonun ağırlığının \%40'ını oluşturur ve tüm bunlar kompozit malzeme kullanımına potansiyel oluşturur. Kaporta, kapılar, tavan ve tamponlar kompozit kullanımına aday diğer yerlerdir. Askeri araçlarda koltuklar, taban panel bileşenleri, gövde panelleri, takviye yapılar, motor kaplamaları, tekerlek yuvaları, korkuluk ve çamurluklar ağırlığı azaltmak üzere kompozit malzemelerden faydalanılabilecek diğer kısımlardır. Polimer matrisli kompozitler, askeri araçlarda yapısal olmayan kaporta parçalarında, tavan kaplamalarında kullanılır. Cam fiberpolipropilen (PP-GF), akü kutusu, motor kaplaması ve diğer görünmeyen parçalarda kullanılır. Şaside çelik kullanımına alternatif olarak fiber takviyeli kompozit elemanlar kullanılmasıyla \%12 ağırlık azalması sağlanabilir [5].

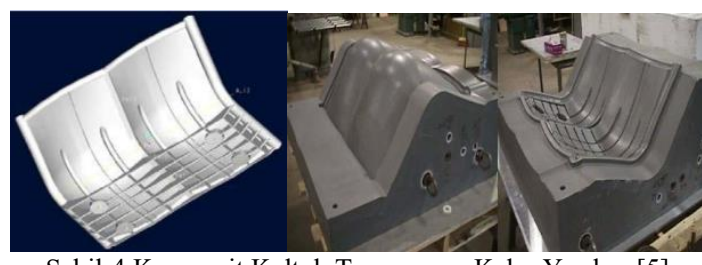

Şekil-4 Kompozit Koltuk Tasarımı ve Kalıp Yarıları [5]

PP-GF dokuma ile düz bir taban ve bu tabana vakum ile 1s1l şekillendirilen hiperbolik laminatın birleştirilmesi sonucu elde edilen form, termoplastik kompozit taban bileşeni imalatında kullanılır. Otobüs tabanında kullanılabilecek bu kompozit, geleneksel çelik-playvud kontraplak kullanımına göre \%20 ağırlık tasarrufu sağlar [5].

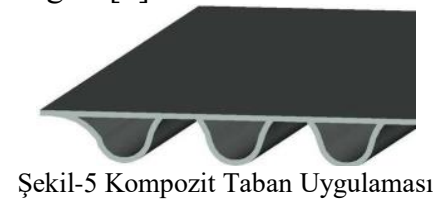

\section{Karbon Fiber Kompozit Kuyruk Konisi}

Hafiflik, güçlülük, uçuş menzilinin ve yük kapasitesinin artması, hizmet süresinin uzun olması korozyon direnci, bakım onarım imkânı ve uygulamaya konulacak teknik yenilikler bakımından kompozit malzemeler, askerî ve sivil uçaklarda giderek artan oranlarda kanat, gövde, yatay/dikey dengeleyiciler, helikopter pervane ve milleri ve diğer bölümlerde yaygın olarak kullanım alanına girmişlerdir[6].

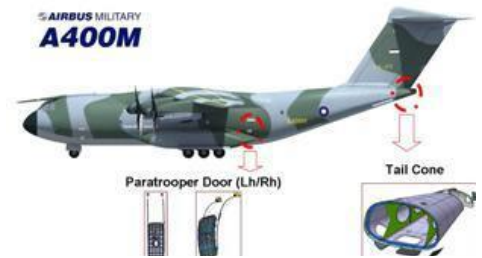

Şekil-6 A400M Askeri Uçağı ve Kuyruk Konisi [6]

Kuyruk konisinin tasarımında optimum ağırlık ve eğilme özellikleri istenir. $\mathrm{Bu}$ sebeple yapının maruz kalabileceği maksimum yükler dikkate alınır. Buna bağlı olarak istenilen yükleme durumlarını karşılayabilecek malzeme ve tasarıma sahip kompozit kuyruk konisi üretilir[6]. 


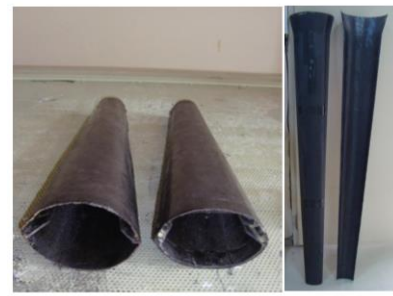

Sekil-7 Farklı Konik Kabuklar

E. Balistik Zırhlarda Kullanılan Kompozitler

Kevlar, 1972 yılında DuPont firması tarafindan piyasaya çıkarılan ve aynı ağırlıktaki çelikten beş kat daha sağlam sloganıyla tanınan bir elyaftır. Kevlar yanmaya karşı dirençli olmakla beraber, erime ya da akmaya uğramamaktadır. $\mathrm{Bu}$ elyaf aynı zamanda, yüksek elastisite modülü, yüksek çekme gerilimi, kimyasallara karşı dayanıklılık, üst düzey ssıl özellik ve boyutsal kararlılık gibi avantajları sayesinde günümüzde birçok uygulamada yaygın olarak kullanılmaktadır. bu özellikleri sayesinde Kevlar, gemi inşası, basınçlı kaplar, spor ürünleri, 1sıl dayanıklılık gerektiren iş kıyafetleri, yangın battaniyeleri, motosiklet ve uçak gibi araçlar için gerekli yüksek hız lastiği, konveyör kayışları ve hidrolik hortumları gibi birçok günlük uygulamanın yanı sıra kurşungeçirmez yelek ve kask imalatı, araç koruması ve stratejik ekipman kalkanı gibi hayati koruma gerektiren uygulamalarda da yaygın bir şekilde kullanılmaktadır [7].
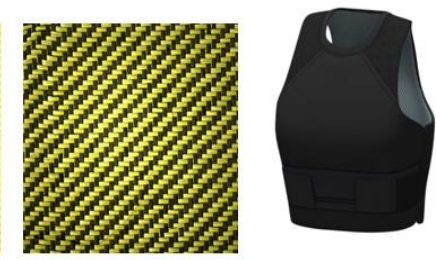

Şekil-8 Aramid Elyaf, Karbon-Aramid Elyaf ve Kompozit Zırh

F. Askeri Helikopterlerde Kompozit Uygulamaları

Askeri helikopterlerde kompozit uygulamaları 1970'li yıllarda başlamıştır. Alüminyum alaşımlarına alternatif olarak kullanılması düşünülen kompozitlerle dayanımdan ödün vermeden helikopterlerin ağırlıklarının azaltılması hedeflenmiştir. Günümüze kadar olan süreçte, maliyet faktörü de en az performans kadar önem taşıdığından her iki malzeme grubunun da etkin bir biçimde kullanıldığını görmekteyiz. V22 Osprey ordu helikopterinin yapımında ağıllıkça \%57 oranında başta karbon olmak üzere takviyelendirilmiş plastik malzeme kullanılmıştır[8].

Takviyelendirilmiş plastikler yeni nesil tilt-rotor hava taşıtlarında daha da büyük rol alacaktır [11].

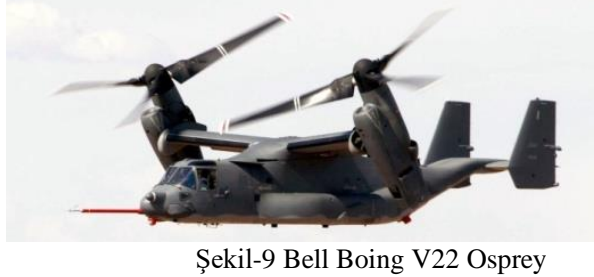

Gövdesinde kompozit kullanılan ilk helikopterlerden birisi de EH 101 Merlin modelidir. Bu modelin gövdesinde cam ve karbon fiber takviyeli plastik kullanılmıştır. Bu yapı ataklarda, normal uçuş ve alçalma anındaki gerilmelere dayanabilmektedir. Aynı gövdenin metalden üretilmesi, pek çok ek ve birleştirme elemanını gerektirmektedir. Ayrıca eşdeğer kompozit bir yapı, daha sağlam ve dayanıklı olmaktadır[8].

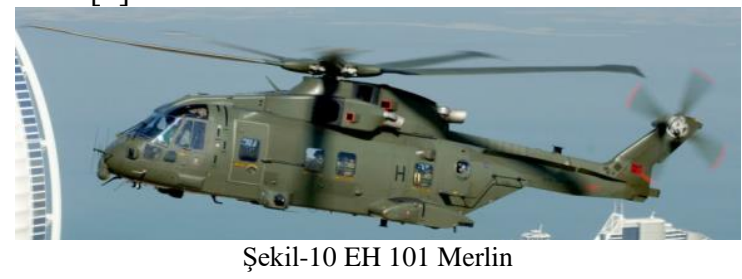

NH 90 askeri nakliye helikopterinin de gövdesinin ön kısmında karbon-epoksi kompozit kullanılmıştır. Genel olarak karmaşı şekilli olarak nitelendirilebilecek bu bölgede metal kullanımında gerekli olacak olan birleştirme ve eklemelere, kompozit kullanımı ile gerek kalmamıştır[8].

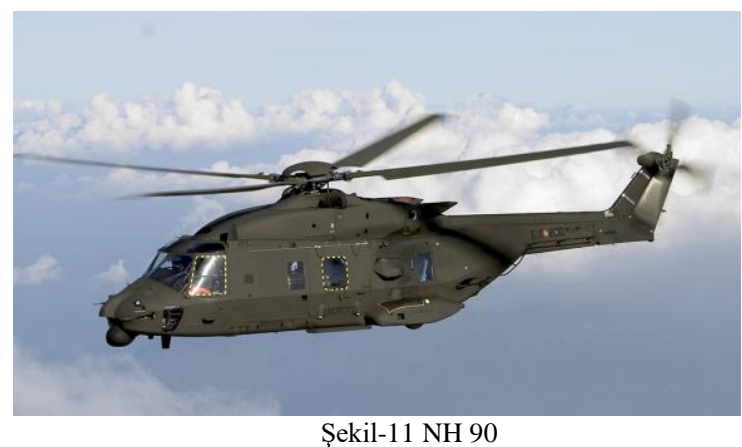

Avrupanın kullanıma giren en son askeri kargo uçağı A400M, \%30 plastik malzeme kullanılarak üretilmişitir [9].

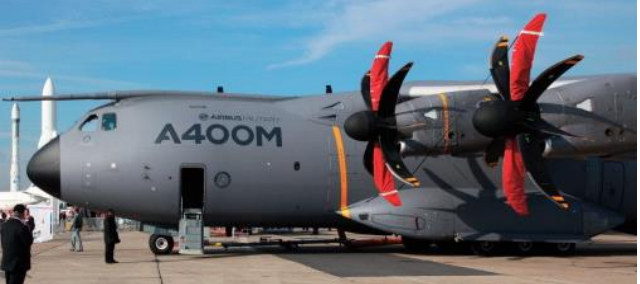

Şekil-7 A400M askeri kargo uçağ

\section{G. Polimer Beton Kompozitler}

Hızlı dayanım eldesi sağlayan polimer beton kompozit, kumsal ve sahil bölgelerdeki askeri uygulamalar için doğal ve sentetik reçineler kullanılarak geliştirilmiştir. Bu kompozit malzeme, karayollarının inşası ve onarımında, helikopter ve uçak pistlerinde, füze rampalarının koruyucularında, ordu tanklarının test yataklarında ve diğer askeri uygulamalarda askeri birliklerin çölde, kıyı ve yüksek rakımlı bölgelerde hareket kabiliyetini arttırmak için kullanılır [10]. 


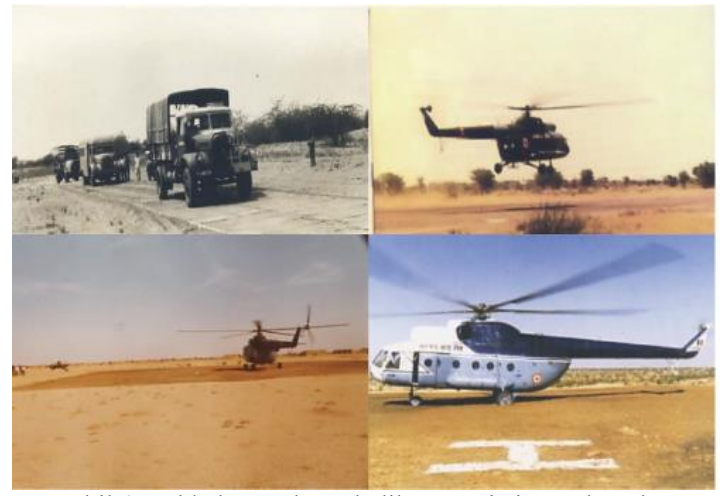

Şekil-8 Çölde karayolu ve helikopter pisti uygulamaları

H. Kompozit Panel Sistemler

Askerleri füze ve diğer balistik tehditlerden korumak için askeri çadırlara uygulanabilen kompozit panel sistemler, İleri Mühendislik Ahşap Kompozit Merkezi (Maine Üniversitesi, ABD) tarafindan geliştirilmiştir. Modüler balistik koruma sistemleri, Amerikan ordu çadırlarına uygulanabilmektedir ve askerleri geçici karargâhlarda balistik saldırılardan korumak için tasarlanmıştır[11].

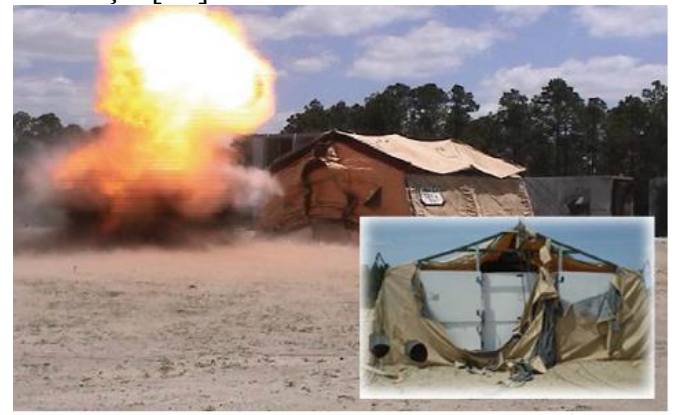

Şekil-9 Askeri Çadırlara Uygulanabilen Kompozit Panel Sistemler

\section{Kompozit Sigorta Röle Kutusu}

Akeri araçlarda kullanılmak üzere çok parçalı elektromekanik modüller, esasen cam fiber takviyeli poliamidden imal edilir. Sistem, bir adet motor bölmesinde ve bir adet de aracın içinde olmak üzere iki kutudan oluşur. Bu iki modül, aracı kısa devrelere karşı korurken araca gücü dağıtır ve aracın tüm elektronik sistemini merkezi olarak kontrol eder. Motor bölmesindeki kutu, kompleks bir şekle sahiptir. Tam boyutlu olarak imal edilen bağlantı levhası, bileşeni hafifleştirir. Mekanik zorlamalara karşı son derece dayanıklıdır; araca bağlamak için tek bir vida yeterli olmaktadır. Yapı aynı zamanda güç dağıtım modülü gibi fonksiyonel parçaları, herhangi bir vidalı bağlantı kullanmadan sabitlemek için çeşitli geçmeli bağlantılara ve tutma sistemine sahiptir. Motor bölmesindeki kutunun bu malzemeden yapılması halinde kimyasallara karşı yeterli direnç ve yeterli tokluk sağlanmış olur [12].

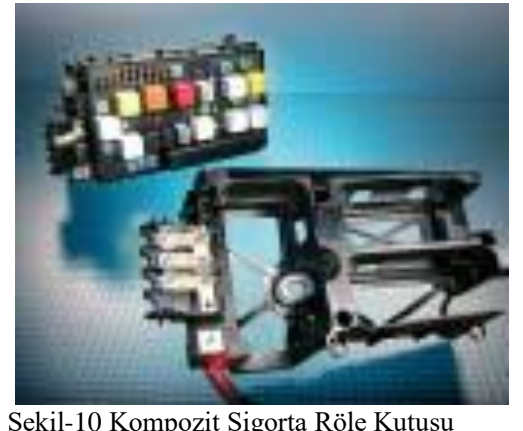

\section{J. Kompozit Filtre Muhafazası}

Geleneksel yöntemlerle dökme demirden imal edilen filtre muhafazası, yaklaşık $120 \mathrm{~kg}$ ağırlığında olmaktadır. Aynı parçanın kompozit malzemeden yapılarak ağırlı̆̆ının 16 kg'a düşürülmesi hedeflenmiştir. Ayrıca kompozit malzeme kullanımıyla metal malzemeye göre korozyon direncinde önemli derecede iyileştirme sağlanacaktır. $\mathrm{Bu}$ parçanın imalatında epoksi reçine ve dört açılı cam fiber takviye kullanılmıştır [13].

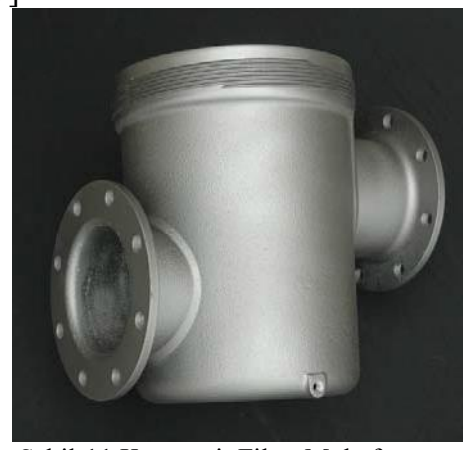

Şekil-11 Kompozit Filtre Muhafazası

\section{K. Kompozit Askeri Tekneler}

Bir takım görevleri yerine getirmek üzere 11 metre uzunluğunda kompozit askeri tekne üretilmiştir. Bu tekne, güçlü robüst yapı için ileri kompozit malzemeler kullanılarak imal edilmiş olup toplam ağırlığı önemli ölçüde azaltılmıştır. Ağırlığın azaltılması, doğrudan daha fazla taşıma kapasitesi ve hız demektir. Aynı zamanda korozyon direncini iyileştiren kompozit malzeme kullanımı, periyodik bakım maliyetlerini azaltmaktadır. Ayrıca imal edilen bu tekne, askeri taşıma teknesi veya devriye teknesi olarak konfigüre edilebilir. Üzerine hızlı bir şekilde bir dizi konuşlandırma yapılacak şekilde dizayn edilmiştir [14].

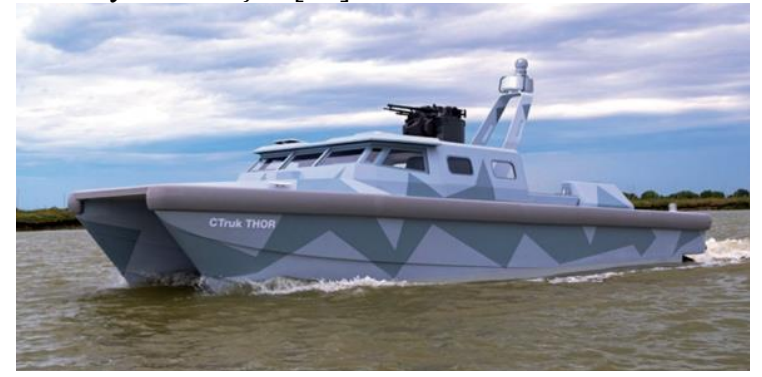

Şekil-12 THOR Kompozit Askeri Tekne

III. Sonuç 
Son yillarda, konvansiyonel malzemelere alternatif olarak kompozit malzemeler; yüksek yoğunluk / mukavemet oranı, gelişmiş imalat teknolojisi, spesifik dayanım ve yüksek korozyon direnci gibi özellikleri nedeniyle savunma sanayinde yaygın olarak kullanılmaktadır. Gerek malzeme ve gerekse imalat teknolojilerindeki yeni gelişmeler ile ülkemiz, savunma sanayinde önemli yer alacaktır.

\section{Kaynaklar}

[1]Akdoğan Eker, A. "Kompozit Malzemeler" YTÜ Ders Notları, İstanbul, (2014)

[2]Aran, A. "Elyaf Takviyeli Karma Malzemeler" İTÜ Fen Bilimleri Enstitüsü, MK-575 Ders Notları, İstanbul, (1990).

[3]Erbay, K. "Silah Gövdeleri İçin Polimer Esaslı Kompozit Malzeme Üretimi ve Özelliklerinin İncelenmesi” Yüksek Lisans Tezi, KTÜ Fen Bilimleri Enstitüsü, Trabzon (2009)

[4]Reinforced Plastics, "Composites Fight For Share of Military Applications" (Mayıs 2005). Cilt 49, Sayı 5, May 2005, Sayfa 18-22

[5]Vaidyaa, U.K., Pillay, S.B., Thattai, K. B. and Ning, H. "Advanced Reinforced Thermoplastic Composites for Mass Transit and Heavy Truck Applications" International Journal of Vehicle Structures \& Systems 4(3), 0975-3060, 92-95, (2012).

[6]Kavrar, D. "Fabrication and Characterization of a Helicopter Composite Tail Cone" Yüksek Lisans Tezi, İTÜ, Metalurji ve Malzeme Mühendisliği, İstanbul (2012)

[7]Özgültekin, S.E. "Balistik Zırhlarda Kullanılan Kompozit Malzeme Kombinasyonlarının İncelenmesi" Yüksek Lisans Tezi, Sakarya Üniversitesi Fen Bilimleri Enstitüsü, Sakarya, (2012).

[8]Reinforced Plastics, "Moving Into Partnership on Helicopters" (Haziran 2001).

[9]Reinforced Plastics, “Composites Flying High” Mayıs/Haziran 2014

[10] Ram Gopal, "Polymer Concrete Composites for Enhancement of Mobilityof Troops in Desert Operations" Materials Science and Engineering B 132 129-133 (2006).

[11] Reinforced Plastics, "Composites Make Army Tents Safer" (Kasım 2007).

[12] Reinforced Plastics, "Improving Army Vehicles, Thermoplastic Suits Complex Modules" Nisan, 2006

[13] Reinforced Plastics, "Filter Pot Features Integral Thread" Ocak 2008

[14] Reinforced Plastics, "CTruk Launches Composite Multi-Purpose Military Vessel” Kasım/Aralık 2013 